\title{
Development of a Measurement Scale to Evaluate Self-Care Stability for Patients Diagnosed with Type 2 Diabetes at an Older Age
}

\author{
Eri Konda ${ }^{1}$, Michiko Inagaki $^{2 *}$, Keiko Tasaki ${ }^{2}$ \\ ${ }^{1}$ Department of Chronic Care, Division of Health Sciences, Graduate School of Medical Sciences, Kanazawa University, Kanazawa, \\ Japan \\ ${ }^{2}$ Department of Clinical Nursing, Faculty of Health Sciences, Institute of Medical, Pharmaceutical and Health Sciences, Kanazawa \\ University, Kanazawa, Japan \\ Email: Eri.konda@komatsu-u.ac.jp, *inagaki@mhs.mp.kanazawa-u.ac.jp
}

How to cite this paper: Konda, E., Inagaki, M. and Tasaki, K. (2018) Development of a Measurement Scale to Evaluate Self-Care Stability for Patients Diagnosed with Type 2 Diabetes at an Older Age. Open Journal of Nursing, 8, 905-917.

https://doi.org/10.4236/ojn.2018.812068

Received: November 28, 2018

Accepted: December 26, 2018

Published: December 29, 2018

Copyright (c) 2018 by authors and Scientific Research Publishing Inc. This work is licensed under the Creative Commons Attribution International License (CC BY 4.0).

http://creativecommons.org/licenses/by/4.0/

(c) (i) Open Access

\begin{abstract}
Objectives: For the medical care of older adults diagnosed with type 2 diabetes later in life, it is necessary to provide medical staff support considering their life stage and to ensure that they live a stable life without fatigue. However, there is no measure for evaluating whether older diabetic patients have a stable life at the time of diagnosis. This study aimed to develop a scale to evaluate self-care stability for diabetic patients and to verify its reliability and validity. Methods: A cross-sectional study was conducted at four hospitals in Japan. A draft scale comprising 39 items was developed to identify patients' stability of diabetes self-care in life. A total of 69 patients diagnosed with diabetes for the first time at age 60 or older responded effectively to questionnaires. Results: As a result of item analysis and factor analysis, seven factors comprising 20 items were extracted. The cumulative contribution ratio before rotation was $70.577 \%$. Cronbach's $\alpha$ was 0.700 overall. The total score on this scale and the sum of the revised Philadelphia Geriatric Center Morale Scale scores were significantly positively correlated $(r=0.379)$. On comparing the total scale score based on glycated hemoglobin level, the scale score of the stable group was found to be higher. Therefore, this scale was found to be reliable and valid. Conclusions: This scale may have utility in the measurement of self-care stability in patients diagnosed with type 2 diabetes later in life.
\end{abstract}

\section{Keywords}

HbA1c, Older Adults, Self-Care, Type 2 Diabetes 


\section{Introduction}

Worldwide, the proportion of people with diabetes is continuously increasing, and it has become very important to take necessary action to maintain good glycemic control from the viewpoint of prolonging the healthy life span of these individuals and suppressing medical expenses. According to the International Diabetes Federation (IDF), the prevalence of diabetes is increasing exponentially, worldwide; 425 million people have the disease, and 98 million of them are aged 65 - 79 years [1]. Hyperglycemia is a risk factor for coronary artery disease [2], stroke [3] and heart failure [4] in older adults with diabetes. In addition, such people are prone to developing dementia [5] [6] [7] [8], depression [9] [10], a decline in the activities of daily living [11], sarcopenia [12] and flails [13]. Therefore, the problems associated with diabetes are more serious in older patients, and their influence on medical costs is also great.

In the diabetes treatment guidelines for older adults, although the importance of medical support considering psychological and social situations as well as physical aspects has been stated, concrete measures to cope with diversification and individualization have not been established. The guidelines for the treatment of diabetes in older adults, as presented by the American Diabetes Association (ADA) and IDF, describe the need to consider the individual aspects in patients such as function, coexisting disease, dementia, and social support, and include three levels of glycemic control targets [14] [15]. However, it has also been pointed out that support for the psychological and social aspects is inadequate, and guidelines for the support of psychological aspects are lacking [16] [17].

In the treatment of diabetes, patients need to attend to their diets, engage in physical activity, and inject insulin, among other measures. In other words, patients need to reconstruct their lifestyle habits to treat diabetes. Older adults are less likely to be able to adapt to this condition or new environments due to psychological and physical decline [18], and their lifestyle habits have been cultivated over many years. Therefore, it is believed that reconstructing their life in order to treat diabetes is quite difficult. In fact, it has been observed that patients who are diagnosed with type 2 diabetes at an older age feel that the various changes produce an instability in their daily lives, which is caused by the overlapping of diabetes and age, and that they are exhausted from the daily experiences of a diabetic life [19]. Therefore, considering their life stage, it can be said that patients who are diagnosed with diabetes at an older age need to develop a positive approach to lead a life of stable self-care. However, concrete support methods to ensure this have not been established yet.

Accordingly, our objective was to develop a scale that evaluates the self-care stability in patients diagnosed with type 2 diabetes at an older age, and to confirm the reliability and validity of this scale.

\section{Materials and Methods}

\subsection{Study Design and Sample Selection}

Older adults diagnosed with type 2 diabetes for the first time at age 60 years or 
older, who had received diabetes treatment for more than 6 months and were either inpatients or outpatients, were included. Patients who had trouble responding to the questionnaire due to a decline in cognitive function were excluded.

The investigation period was from January 2016 to September 2016.

Ethical approval to conduct this study was provided by the institutional review board of Kanazawa University (approval number: 613-1, 2). All patients provided written informed consent to take part in the study before data collection.

\subsection{Procedures for Instrument Development}

A narrative on self-care stability in diabetic patients was extracted from a previous study titled, "Self-care learning in type 2 diabetes patients aged 65 years or older at the time of diagnosis" [19], and a total of 39 questionnaire items were developed.

With regard to the 39 question items, to enhance content validity, we examined the method of expression of the questions and the ease of answering them. We amended the question items with the aid of three diabetes nursing experts who have research experience and are knowledgeable on the analysis course included in previous studies.

Furthermore, in order to enhance surface validity, four older patients with type 2 diabetes at the time of diagnosis, selected on the basis of their age and sex, rated the question items in terms of the time required to respond and the ease of answering.

As a result, none of the items was deleted; the expression method was modified for item 6 only, and a draft comprising a total of 39 items, in which the expression was refined, was constructed.

\subsection{Scoring of the Instrument}

All items in the scale were rated on a 5-point Likert scale. Respondents were instructed to respond to each item by circling one of the following: $1=$ disagree, 2 $=$ slightly disagree, $3=$ unsure, $4=$ slightly agree, or $5=$ agree. The total score was calculated by summing all the item scores. Higher scores were indicative of participants evaluating themselves as being capable of ensuring diabetes self-care stability.

In accordance with previous research, for the 25 items that were considered to be the cause of unstable self-care in life (when $5=$ agree was selected), reverse processing was performed during scoring. In the subsequent procedure, 25 items were scored by inverse processing and analyzed.

Furthermore, in order to simultaneously capture a patient's medical behavior and psychological aspects, eight items were scored in four pairs. In the scoring method, scores of 1 to 5 were allocated to each of the two items; only one item was scaled 10 times, and the scores of the two items were added. We evaluated 
25 answers that were a combination of causes and resulted from the viewpoint of whether they were stable or not, and these were converted to 1 to 5 points again.

The number of items to be analyzed after scoring was 35 .

\subsection{Research Items}

\section{Basic attributes:}

Of the 13 items investigated as basic attributes, questions on the first nine (age, sex, age at diabetes diagnosis, height, weight, diabetes treatment contents, presence or absence of hospitalization due to diabetes, household, and presence or absence of occupation) were answered by the patients themselves. Data on the latter four items (latest glycated hemoglobin (HbA1c) level, drug therapy contents of diabetes, presence or absence of three major complications, and presence of diseases other than diabetes) were collected from medical records with patients' consent.

Draft scale:

A draft scale comprising 39 items was developed to identify self-care stability in a diabetic patient's life.

Revised version of the Philadelphia Geriatric Center (PGC) Morale Scale:

This scale, developed by Lawton, comprises 17 items and measures the subjective quality of life (QOL) of older people through the three aspects of "agitation", "lonely dissatisfaction", and "attitudes toward own aging" [20]. The Japanese version of this measure was used [21].

\subsection{Method of Data Collection}

We requested collaboration in our research from medical institutions in Japan. Surveys were conducted at the four facilities that had approved our request. One researcher selected patients who were diagnosed with diabetes at age 60 years or older and had a medical treatment period of 6 months or more based on data obtained from medical records. A researcher or nurse who understood the purpose of the research explained its contents to the participants and stated that participation in the study was voluntary. Then, the questionnaire was handed out directly. Responses to the questionnaire were written out on the spot and collected directly. For patients who found it difficult to respond due to aging-related visual impairment, a researcher read out the questionnaire items and supported the answers.

\subsection{Statistical Analyses}

All statistical analyses were performed using SPSS Statistics for Windows, version 22 (IBM Corp., Armonk, NY, USA). First, item analysis was conducted on the items developed independently, and the items to be considered for factor analysis were narrowed down upon. For the remaining items, factor analysis was carried out to examine the validity of the composition concept. Regarding the obtained factor structure, confirmation of Item-to-Total correlation (I-T corre- 
lation) and calculation of Cronbach's $\alpha$ coefficient were performed to examine internal consistency.

To confirm concurrent validity, the correlation coefficient between the total score on the developed scale and on the revised PGC Morale Scale was calculated. Furthermore, to better understand if the quality of self-care worsened, participants were divided into two groups based on their $\mathrm{HbAlc}$ values, and the difference in the mean values of the total scores on the developed scale between the two groups was tested.

\section{Results}

\subsection{Sample Characteristics}

Questionnaires were distributed to 78 older adults diagnosed with type 2 diabetes for the first time at age 60 years or older, and effective responses were obtained from 69 (effective response rate: 88.5\%).

Details of the sample characteristics are shown in Table 1.

Table 1. Sample characteristics $(n=69)$.

\begin{tabular}{|c|c|c|}
\hline Characteristic & $\begin{array}{c}\text { Overall average } \\
\text { (Standard deviation) }\end{array}$ & $\begin{array}{c}\text { Number of respondents } \\
\text { (Rate) }\end{array}$ \\
\hline Age & \multirow{4}{*}{$75.8( \pm 6.3)$ years } & \\
\hline $60-69$ years & & $13(18.8)$ \\
\hline $70-79$ years & & $35(50.8)$ \\
\hline 80 - 89 years & & $21(30.4)$ \\
\hline \multicolumn{3}{|l|}{ Sex } \\
\hline Male & & $36(52.2)$ \\
\hline Female & & $33(47.8)$ \\
\hline Age at diabetes diagnosis & $65.8( \pm 5.3)$ years & \\
\hline Duration of diabetes & $9.7( \pm 6.7)$ years & \\
\hline \multicolumn{3}{|l|}{ HbAlc } \\
\hline $5.0 \%-5.9 \%$ & \multirow{5}{*}{$6.8( \pm 1.0) \%$} & $10(14.5)$ \\
\hline $6.0 \%-6.9 \%$ & & $34(49.3)$ \\
\hline $7.0 \%-7.9 \%$ & & $18(26.1)$ \\
\hline $8.0 \%-8.9 \%$ & & $3(4.3)$ \\
\hline $9.0 \%-9.9 \%$ & & $4(5.8)$ \\
\hline BMI & $24.1( \pm 4.0) \mathrm{kg} / \mathrm{m}^{2}$ & \\
\hline \multicolumn{3}{|l|}{ Diabetes treatment contents } \\
\hline Diet therapy & & $50(72.5)$ \\
\hline Exercise therapy & & $41(59.4)$ \\
\hline Oral drug administration & & $59(85.5)$ \\
\hline Injection drug administration & & $15(21.7)$ \\
\hline No action & & $1(1.4)$ \\
\hline \multicolumn{3}{|l|}{ Three major complications } \\
\hline Either exists & & $34(49.3)$ \\
\hline None & & $8(11.6)$ \\
\hline Unknown & & $27(39.1)$ \\
\hline \multicolumn{3}{|l|}{ Hospitalization due to diabetes } \\
\hline Present & & $35(50.7)$ \\
\hline None & & $33(47.8)$ \\
\hline
\end{tabular}


Continued

\begin{tabular}{cc}
\hline Household & \\
Lives alone & $14(20.3)$ \\
Lives with one other person & $27(39.1)$ \\
Lives with two or more people & $28(40.6)$ \\
Occupation & \\
Employed & $14(20.3)$ \\
Unemployed & $55(79.7)$ \\
\hline
\end{tabular}

BMI, body mass index; HbAlc, glycated hemoglobin.

\subsection{Item Analysis}

For each question item developed, the average value and standard deviation were calculated, and we sought to confirm the presence of a ceiling effect (average value + standard deviation $>5$ ) and floor effect (average value - standard deviation $<1$ ). A ceiling effect was observed for eight items (items $1-2$, item 4 , item 5 , item 6 , items $7-8$, item 25 , item 33 , and item 39); none of the items had a floor effect. On examining the contents of the eight items with a ceiling effect, we considered that each question item was important for the measurement of whether or not the older patients with diabetes practice stable self-care. Therefore, the eight items with a ceiling effect were also analyzed.

Spearman's rank correlation coefficient was calculated to investigate inter-item correlations. There was a significant correlation between items 13 and 14 , and between items 21 and 22 , with $\mathrm{p}<0.01$, and the correlation coefficients were quite high, at $r=0.622$ and $r=0.744$, respectively. Items 13 and 21 were excluded from the analysis because their meaning seemed to overlap, as a result of which 33 items were analyzed.

\subsection{Construct Validity}

The non-weighted least squares method was used and exploratory factor analysis using promax rotation was performed for 33 items.

Initially, a test was conducted to evaluate the validity of the factor analysis. The Kaiser-Meyer-Olkin sample validity measure was 0.625 . Since this can be judged to be valid at a measure of 0.5 or more [22], a reasonable sample size was deemed to have been secured. In the Bartlett sphericity test, $p<0.01$ was obtained, which was significantly different from that in the identity matrix. Accordingly, the factor analysis was judged as appropriate.

The first factor analysis was conducted on 33 items, and one item with a factor load exceeding 1 was excluded. The second factor analysis was carried out on 32 items. Six items with low commonality (less than 0.4 ) and six with a low factor loading (less than 0.4) were excluded. Since one of the items was duplicated, a total of 11 items were excluded. The third factor analysis was conducted on 21 items. There were eight items with low commonality and low factor loading (0.3 or more, and less than 0.4 , respectively) and one item with very low factor loading (less than 0.3). However, only one item with a factor loading value lower 
than 0.3 was excluded from the item content and factor structure. For the remaining 20 items, a fourth factor analysis was conducted. All items showed a factor loading of 0.3 or higher. Factor analysis was thus terminated.

Two characteristics were observed as features of the items that dropped out during factor analysis. First, items that indicate that the responsibility for self-care is external, such as "I feel that I am able to exist now thanks to people around me" (item 4), dropped out. Other items indicating a lack of diligence in self-care, such as "In my self-care, I may get lazy before I confront pain" (item 10), dropped out.

A 7-factor structure was adopted in accordance with the Scree plot criterion and Kaiser-Guttman rule. The cumulative contribution ratio before rotation in the seven factors with the 20 items was $70.577 \%$.

The correlation between factors 1 and 2 was $r=0.445$, between factors 1 and 5 was $r=0.363$, and between factors 1 and 6 was $r=-0.320$, suggesting moderate correlation. No other correlation was recognized.

Factor 1 comprised four items and was named "Dietary restrictions limit the rest of one's life that was expected to be lived in a free and rich manner". Factor 2 comprised five items and was named "Persisting sense of inadequacy despite following self-care as closely as any older adult". Factor 3 comprised two items and was named "Matching with self-image of diabetes". Factor 4 comprised two items and was named "Denial of one's own diabetes diagnosis". Factor 5 comprised three items and was named "One's own way of living with diabetes as an escape route". Factor 6 comprised two items and was named "Hopes of being one's usual self at the end of life". Factor 7 comprised two items and was named "Challenge to aging in a healthy manner". The final factor structure and factor correlation matrix are shown in Table 2.

Table 2. Results of the factor analysis. Pattern matrix was developed using the non-weighted least squares method and promax rotation (20 items).

\begin{tabular}{|c|c|c|c|c|c|c|c|}
\hline \multirow[b]{2}{*}{ Factors and items } & \multicolumn{7}{|c|}{ Factor loading } \\
\hline & 1 & 2 & 3 & 4 & 5 & 6 & 7 \\
\hline \multicolumn{8}{|c|}{ Factor 1: Dietary restrictions limit the rest of one's life that was expected to be lived in a free and rich manner } \\
\hline 22R. Feel life is being limited by restrictions on eating, that is living itself. & 0.806 & 0.204 & 0.010 & 0.179 & -0.226 & -0.009 & -0.012 \\
\hline 19R. Feel miserable that food intake is restricted. & 0.805 & -0.026 & 0.133 & 0.050 & -0.045 & 0.214 & 0.079 \\
\hline 20R. Not satisfied with current life working on diet therapy. & 0.775 & 0.070 & -0.045 & -0.100 & 0.046 & 0.118 & 0.198 \\
\hline $\begin{array}{l}30-31 \mathrm{R} . \text { Meals are the greatest pleasure in old age. It is very arduous } \\
\text { when meal intake is restricted. }\end{array}$ & 0.697 & -0.063 & -0.120 & -0.145 & 0.178 & -0.092 & -0.106 \\
\hline \multicolumn{8}{|c|}{ Factor 2: Persisting sense of inadequacy despite following self-care as closely as any older adult } \\
\hline 14R. The fear of diabetes complications never leaves my head. & 0.050 & 0.717 & 0.213 & -0.055 & -0.001 & -0.148 & 0.121 \\
\hline $\begin{array}{l}24 \mathrm{R} \text {. I am trying hard to perform self-care but I feel my efforts are not } \\
\text { rewarded. }\end{array}$ & 0.019 & 0.714 & -0.018 & 0.037 & 0.102 & 0.209 & -0.036 \\
\hline $\begin{array}{l}\text { 25R. Even after becoming a diabetic patient, I feel that I am at the center } \\
\text { of my healthcare. }\end{array}$ & -0.044 & 0.598 & 0.055 & -0.241 & -0.193 & 0.136 & -0.294 \\
\hline
\end{tabular}




\section{Continued}

15R. The feeling of insufficiency is stronger than the sense of trying hard enough regarding self-care behaviors.

38R. I desire to escape from my diabetes condition.

\section{Factor 3: Matching with self-image of diabetes}

$28 \mathrm{R}$. Feel there is a difference between the health image suggested by the medical staff and my own health image.

37R. Before the diagnosis, I had a feeling that I had diabetes.

\section{Factor 4: Denial of one's own diabetes diagnosis}

34R. I was not supposed to develop diabetes.

36R. I am unwilling to accept my diabetes diagnosis.

Factor 5: One's own way of living with diabetes as an escape route

16R. In front of medical staff, I cannot be proud of the immense efforts I have put in regarding diabetes self-care.

12R. Sometimes, I overlook the insufficiencies in diet therapy.

9R. Sometimes, I participate in unreasonable acts (e.g., going on a mad binge) that deviates from medical treatment behaviors.

\section{Factor 6: Hopes of being one's usual self at the end of life}

6. Hope to greet the end of life without being concerned with diabetes.

33. I am convinced that I developed diabetes due to my own behavior.

\section{Factor 7: Challenge to aging in a healthy manner}

3. Considering both my current age and diabetes condition, I feel I am still healthy.

5. I desire to protect my own health even in my current age.

Correlation among factors

$\begin{array}{lllllll}0.062 & 0.505 & 0.215 & 0.037 & 0.146 & -0.149 & 0.145 \\ 0.014 & 0.408 & -0.321 & 0.194 & 0.067 & -0.202 & 0.148\end{array}$

$\begin{array}{lllllll}-0.021 & 0.043 & 0.807 & -0.014 & 0.131 & -0.026 & -0.169\end{array}$

$\begin{array}{lllllll}0.065 & 0.106 & 0.567 & 0.050 & 0.030 & -0.046 & 0.137\end{array}$

$\begin{array}{lllllll}-0.053 & -0.094 & 0.144 & 0.886 & 0.030 & 0.036 & -0.145\end{array}$

$\begin{array}{lllllll}0.024 & 0.071 & -0.098 & 0.593 & 0.011 & 0.134 & 0.062\end{array}$

$\begin{array}{ccccccc}-0.150 & 0.142 & 0.151 & 0.038 & 0.836 & 0.123 & 0.039 \\ 0.163 & 0.248 & -0.163 & -0.013 & 0.517 & -0.023 & -0.284 \\ 0.189 & -0.194 & 0.103 & -0.001 & 0.389 & -0.141 & 0.098\end{array}$

$\begin{array}{ccccccc}0.215 & -0.032 & -0.024 & 0.118 & 0.036 & 0.892 & -0.108 \\ -0.383 & 0.201 & -0.141 & 0.055 & 0.044 & 0.412 & 0.192\end{array}$

$\begin{array}{ccccccc}0.090 & 0.073 & -0.056 & -0.037 & -0.026 & -0.083 & 0.698 \\ 0.028 & -0.245 & 0.070 & -0.158 & 0.142 & 0.246 & 0.319 \\ 1 & 2 & 3 & 4 & 5 & 6 & 7 \\ 1.00 & 0.445 & 0.101 & 0.025 & 0.363 & -0.320 & -0.062 \\ & 1.00 & -0.019 & 0.032 & 0.267 & -0.169 & -0.233 \\ & & 1.00 & 0.174 & 0.229 & -0.079 & 0.169 \\ & & & 1.00 & -0.038 & -0.187 & 0.053 \\ & & & & 1.00 & -0.209 & 0.127 \\ & & & & & 1.00 & 0.075 \\ & & & & & & 1.00\end{array}$

Items marked with " $\mathrm{R}$ " are not "stable" worded items and are reversely scored.

\subsection{Reliability}

I-T correlation and Cronbach's $\alpha$ coefficient were calculated to investigate the internal consistency of the developed scale.

As a result of confirming the I-T correlation for the final 20 items, 15 items showed a significant positive correlation with the total score $(\mathrm{p}<0.05)$ and the correlation coefficient was $r=0.239$ - 0.613. In item 5, item 6 , item 33, item 34R, and item $25 \mathrm{R}$, the correlation coefficient was lower than 0.2 , and the correlation with the total score was very weak. However, in all five items in which the correlation was very weak, correlations with other items were recognized at $\mathrm{p}<0.05$, 
and the contents of the items were also examined; the item was not deleted.

Cronbach's $\alpha$ coefficient was 0.419 to 0.834 for each factor, and $\alpha=0.700$ as a whole (Table 3).

\subsection{Concurrent Validity}

Spearman's rank correlation coefficient between the total score on the developed scale and the total score on the revised PGC Morale Scale was calculated to examine the concurrent validity. A significant positive correlation was observed at $\mathrm{p}<0.01(\mathrm{r}=0.379)$.

The total score on the developed scale was compared by grouping participants based on their HbA1c levels. Based on the target blood glucose control value for older adults with diabetes, as presented by the ADA, the Japan Geriatrics Society, and the Japan Diabetes Society, those with HbAlc values of $6.0 \%$ to $7.9 \%$ were grouped under stable self-care and those with values $<6.0$ or $\geq 8.0$ were grouped under the unstable self-care ("tight control" or "loose control" groups). A t-test of the differences in the total score average values on the developed scale between the two groups showed $\mathrm{t}=-2.042, \mathrm{df}=67, \mathrm{p}=0.045$, and a significant difference (Table 4).

Table 3. Cronbach's coefficient alpha $(n=69)$ for the developed scale in the evaluation of the stability in self-care among patients diagnosed with type 2 diabetes later in life (20 items).

\begin{tabular}{lc}
\hline \multicolumn{1}{c}{ Factor } & $\begin{array}{c}\text { Cronbach's } \\
\text { coefficient } \alpha\end{array}$ \\
\hline $\begin{array}{l}\text { Factor 1: Dietary restrictions limit the rest of one's life that was expected to be lived } \\
\text { in a free and rich manner }\end{array}$ & 0.834 \\
Factor 2: Persisting sense of inadequacy despite following self-care as closely as any & 0.707 \\
older adult & 0.627 \\
Factor 3: Matching with self-image of diabetes & 0.642 \\
Factor 4: Denial of one's own diabetes diagnosis & 0.583 \\
Factor 5: One's own way of living with diabetes as an escape route & 0.512 \\
Factor 6: Hopes of being one's usual self at the end of life & 0.419 \\
Factor 7: Challenge to aging in a healthy manner & 0.700 \\
\hline
\end{tabular}

Table 4. Difference in the average total score values in the developed scale between the stable self-care and the unstable self-care groups (tight or loose control groups) categorized by HbA1c level $(n=69)$.

\begin{tabular}{|c|c|c|c|c|c|}
\hline & \multicolumn{2}{|c|}{$\begin{array}{c}\text { Stable self-care } \\
(\text { HbA1c: } 6.0 \%-7.9 \%) \\
n=52(75.4 \%)\end{array}$} & \multicolumn{2}{|c|}{$\begin{array}{c}\text { Unstable self-care } \\
(\text { HbAlc }<6.0 \text { or } \geq 8.0 \%) \\
n=17(24.6 \%)\end{array}$} & \multirow[t]{2}{*}{$\mathrm{t}-$ Value } \\
\hline & $\mathrm{M}$ & $\mathrm{SD}$ & $\mathrm{M}$ & $\mathrm{SD}$ & \\
\hline Total score on the scale & 62.79 & 8.941 & 57.88 & 7.415 & $-2.042^{*}$ \\
\hline
\end{tabular}

*Correlation was significant at a 5\% level (both sides). HbA1c, glycated hemoglobin; SD, standard deviation; M, mean. 


\section{Discussion}

\subsection{Validity and Reliability}

The aim of this study was to develop a scale that would allow for the assessment of the self-care stability in diabetic patients' lives and to verify its reliability and validity in patients diagnosed with type 2 diabetes at a later stage in their lives. From the results, the developed scale, comprising seven factors and 20 items, was deemed reliable and valid.

Regarding reliability, Cronbach's $\alpha$ coefficient-the criterion for internal consistency judgment-was 0.419 to 0.834 for each factor. It is desirable to obtain a coefficient of Cronbach's $\alpha$ equal to or greater than 0.7 [23]. For factors 3 to 7 , the Cronbach's $\alpha$ of which was lower than 0.7 , the number of items constituting the factor was as low as 2 or 3. Cronbach's $\alpha$ was 0.700 for the entire scale, and although the $\alpha$ coefficient was somewhat low for each factor, internal consistency was obtained in the scale as a whole, as a result of which its reliability was secured.

In terms of validity, we examined content validity, surface validity, construct validity, and concurrent validity.

Regarding content and surface validity, we followed the procedure in consideration of the contents of the question items with experts knowledgeable in the processes of previous studies, with the modification of expressions pointed out by patients; validity was thus secured.

Regarding the factor analysis that was conducted to examine construct validity, and factor loading representing the degree of association with each factor, there was an association between the item and factor at a value of 0.4 or higher, and no association was found at 0.2 or less [24]. In our study, of the 20 items that finally remained, two items had a factor loading lower than 0.4 , but it was not lower than 0.2 ; construct validity was thus secured.

Regarding concurrent validity, higher scores were obtained on this scale when older adults diagnosed with type 2 diabetes later in life practiced stable diabetes self-care, and in cases in which patients were satisfied despite having to live with the condition and undergoing treatment for it. Therefore, for concurrent validity, the correlation between the scores on this scale and the revised PGC Morale Scale was confirmed. A significant positive correlation $(r=0.379)$ was observed and concurrent validity was established. Furthermore, when the participants were grouped based on their $\mathrm{HbAlc}$ values, the average of the total score on the scale was significantly lower in cases of $\mathrm{HbA1c}$ values $<6.0$ or $\geq 8.0$, which predicted a life of unstable self-care. Therefore, it was confirmed that this scale could measure both subjective and practical aspects of diabetes self-care.

\subsection{Significance of Developing a Measurement Scale to Evaluate Self-Care Stability for Older Diabetic Patients}

Older adults diagnosed with type 2 diabetes later in life have not received much attention to date, and such individuals usually fear the coexistence of diabetes 
and aging. In the absence of proper support in initial education, patients are likely to continue engaging in self-care with feelings of insufficiency [25]. Therefore, the lack of adequate support for stability in diabetes self-care can lead to dissatisfaction among older adults, which can demotivate these patients from practicing diabetes self-care.

The measurement scale for evaluating stability in diabetes self-care we developed is one in which each factor and item expresses a sensation peculiar to older adults, and it is considered to be useful as a concrete means of providing medical care support that is cherished by the patient at that stage in life. In real-world settings, patients may respond to the questionnaire and, accordingly, nurses may be able to evaluate if they are continuously engaged in diabetes self-care with stability. Therefore, the use of a common method to identify how older adults relate to their diabetes diagnosis, aging and the problems raised can support the maintenance of self-care with stability and satisfaction.

\subsection{Adaptation Range of This Scale}

The scale development in this research was conducted in Japanese, and the investigation was not conducted in English. Therefore, it is necessary to examine the scale's reliability and validity when used in English.

\section{Conclusion}

The scale developed in this study was found to be reliable and valid. Therefore, it may have utility in the measurement of self-care stability in patients diagnosed with type 2 diabetes later in life.

\section{Acknowledgements}

We would like to express our deepest gratitude to the patients who participated in our study and provided cooperation. We also appreciate the healthcare professionals who provided various forms of support and advice during this study, especially Ms. Kiyoko Matsui from Kanazawa Medical University, Ms. Tomomi Horiguchi from Kanazawa University, Ms. Yukari Fujita from Komatsu University, and all others whose assistance supported our efforts.

\section{Conflicts of Interest}

The authors declare that they have no competing interests.

\section{References}

[1] IDF (2018) IDF Diabetes Atlas-8th Edition. Key Messages. http://www.diabetesatlas.org/key-messages.html

[2] Kuusisto, J., Mykkänen, L., Pyörälä, K. and Laakso, M. (1994) NIDDM and Its Metabolic Control Predict Coronary Heart Disease in Elderly Subjects. Diabetes, 43, 960-967. https://doi.org/10.2337/diab.43.8.960

[3] Araki, A., Iimuro, S., Sakurai, T., Umegaki, H., Iijima, K., Nakano, H., et al. (2012) Non-High-Density Lipoprotein Cholesterol: An Important Predictor of Stroke and 
Diabetes-Related Mortality in Japanese Elderly Diabetic Patients. Geriatrics \& Gerontology International, 12, 18-28. https://doi.org/10.1111/j.1447-0594.2011.00809.x

[4] Lind, M., Olsson, M., Rosengren, A., Svensson, A.M., Bounias, I. and Gudbjörnsdottir, S. (2012) The Relationship between Glycaemic Control and Heart Failure in 83,021 Patients with Type 2 Diabetes. Diabetologia, 55, 2946-2953. https://doi.org/10.1007/s00125-012-2681-3

[5] Cukierman, T., Gerstein, H.C. and Williamson, J.D. (2005) Cognitive Decline and Dementia in Diabetes-Systematic Overview of Prospective Observational Studies. Diabetologia, 48, 2460-2469. https://doi.org/10.1007/s00125-005-0023-4

[6] Luchsinger, J.A., Reitz, C., Patel, B., Tang, M.X., Manly, J.J. and Mayeux, R. (2007) Relation of Diabetes to Mild Cognitive Impairment. Archives of Neurology, 64, 570-575. https://doi.org/10.1001/archneur.64.4.570

[7] Cheng, G., Huang, C., Deng, H. and Wang, H. (2012) Diabetes as a Risk Factor for Dementia and Mild Cognitive Impairment: A Meta-Analysis of Longitudinal Studies. Internal Medicine Journal, 42, 484-491. https://doi.org/10.1111/j.1445-5994.2012.02758.x

[8] Lu, F.P., Lin, K.P. and Kuo, H.K. (2009) Diabetes and the Risk of Multi-System Aging Phenotypes: A Systematic Review and Meta-Analysis. PLoS One, 4, e4144. https://doi.org/10.1371/journal.pone.0004144

[9] Bruce, D.G., Casey, G., Davis, W.A., Starkstein, S.E., Clarnette, R.C., Foster, J.K., et al. (2006) Vascular Depression in Older People with Diabetes. Diabetologia, 49, 2828-2836. https://doi.org/10.1007/s00125-006-0478-y

[10] Maraldi, C., Volpato, S., Penninx, B.W., Yaffe, K., Simonsick, E.M., Strotmeyer, E.S., et al. (2007) Diabetes Mellitus, Glycemic Control, and Incident Depressive Symptoms among 70- to 79-Year-Old Persons: The Health, Aging, and Body Composition Study. Archives of Internal Medicine, 167, 1137-1144. https://doi.org/10.1001/archinte.167.11.1137

[11] Gregg, E.W., Mangione, C.M., Cauley, J.A., Thompson, T.J., Schwartz, A.V., Ensrud, K.E., et al. (2002) Diabetes and Incidence of Functional Disability in Older Women. Diabetes Care, 25, 61-67. https://doi.org/10.2337/diacare.25.1.61

[12] Park, S.W., Goodpaster, B.H., Strotmeyer, E.S., Kuller, L.H., Broudeau, R., Kammerer, C., et al. (2007) Accelerated Loss of Skeletal Muscle Strength in Older Adults with Type 2 Diabetes: The Health, Aging, and Body Composition Study. Diabetes Care, 30, 1507-1512. https://doi.org/10.2337/dc06-2537

[13] Kalyani, R.R., Tian, J., Xue, Q.L., Walston, J., Cappola, A.R., Fried, L.P., et al. (2012) Hyperglycemia and Incidence of Frailty and Lower Extremity Mobility Limitations in Older Women. Journal of the American Geriatrics Society, 60, 1701-1707. https://doi.org/10.1111/j.1532-5415.2012.04099.x

[14] Kirkman, M.S., Briscoe, V.J., Clark, N., Florez, H., Haas, L.B., Halter, J.B., et al. (2012) Diabetes in Older Adults. Diabetes Care, 35, 2650-2664. https://doi.org/10.2337/dc12-1801

[15] IDF (2013) IDF Global Guideline for Managing Older People with Type 2 Diabetes: 11 Glucose Control Management and Targets. 30-36.

[16] Nakano, M., Moriyama, M. and Sakamaki, H. (2007) A Survey on the Care and Education System Geared towards Standardization of Patient Education for Diabetes. Journal of Health Sciences, Hiroshima University, 6, 118-125.

[17] Shiramizu, M., Sugimoto, T., Mase, Y., Okui, R., Tanaka, H., Kanemathu, Y., et al. (2011) Actual Condition of Diabetes Education Program for Patients with Type 2 Diabetes in Facilities to Which Certified Nurse in Diabetes Nursing or Certified 
Nurse Specialist in Chronic Care Nursing Belongs-Focusing on Contents and Methods of Program. Journal of Japan Academy of Diabetes Education and Nursing, 15, 179-187.

[18] Sakata, M., Kayama, M., Sakuraba, S., Nemoto, H., Matsushita, M. and Yamane, H. (2005) Mental Health Nursing Expert: 10 Psychiatric Care of the Elderly. Nakayama-Shoten, Bunkyo, Tokyo, 38-39.

[19] Koshino, E., Inagaki, M. and Tasaki, K. (2015) Self-Care Learning in Type 2 Diabetes Patients Aged 65 Years or Older at the Time of Diagnosis. Journal of Japan Academy of Diabetes Education and Nursing, 19, 111-120.

[20] Lawton, M.P. (1975) The Philadelphia Geriatric Center Morale Scale: A Revision. The Journals of Gerontology, 30, 85-89. https://doi.org/10.1093/geronj/30.1.85

[21] Koyano, W., Shibata, H., Haga, H. and Suyama, Y. (1989) Structure of the Philadelphia Geriatric Center Morale Scale: What Was Brought by Recent Revision Work. Social Gerontology, 29, 64-74.

[22] Tsushima, E. (2014) Medical Multivariate Data Analysis Learned with SPSS. 8th Edition, TokyoTosho, Chiyoda, Tokyo, 144-145.

[23] Polit, D.F., Beck, C.T. and Kondou, J. (2010) Nursing Research: Principles and Methods. 7th Edition, Second Japanese Edition, Igaku-Shoin Ltd., Tokyo, 434-435.

[24] Tsushima, E. (2014) Medical Multivariate Data Analysis Learned with SPSS. 8th Edition, TokyoTosho, Chiyoda, Tokyo, 188-189.

[25] Takahashi, K., Inagaki, M., Tasaki, K., Matsui, K. and Murakado, N. (2016) Experience of Initial Education and Subsequent Recuperation for Type-2 Diabetes Patients. Journal of Japan Academy of Diabetes Education and Nursing, 20, 183-192. 